\title{
Problematika Pendidikan Agama Islam di Sekolah Umum Tingkat SMA
}

\section{Annuriana Tsalitsa, Siti Nurrahayu Putri, Lusi Rahmawati, Nur Azlina, dan Ulya Fawaida}

Institut Agama Islam Negeri (IAIN) Kudus

Jl. Conge Ngembalrejo, Kudus 59322, Jawa Tengah.

e-mail :a77salisa@gmail.com, sitinurrahayuputri@gmail.com, lusyrahma587@gmail.com,elinpesek2017@gmail.com, dan ufawaida@yahoo.com

\begin{tabular}{|c|c|c|}
\hline Diterima: & Revisi: & Disetujui: \\
24 Januari 2020 & 16 Februari 2020 & 10 April 2020 \\
\hline DOI: & https://doi.org/D0I.10.32332/tarbawiyah.v4i1.1950 \\
\hline
\end{tabular}

Abstract This article describes the problems of Islamic religious education high school level public schools. The formulation of the issues raised is 1) What are the problems of Islamic religious education (PAI) found in high school level public schools 2) How are the solutions to overcome the problems of learning Islamic religious education (PAI) in publics schools at the high school level. This research method is a qualitative research using literature study method, namely by displaying scientific reasoning arguments. The problems of PAI in high school level public schools include low interest learning learners in the PAI learning, lack of time allocation, problems in educators, problem in students, problem in facilities and infrastructure, problem in PAI learning methods, and problem in learning evaluation. Meanwhile so lutions to overco me these problems, including replacing professional teachers, finding PAI teachers who are professional in their fields, every educator is included in events such as seminars, providing facilities and infrastruc ture for the implementation of sufficient Islamic religious teaching practices, educators must master various learning methods so that students easily understand the material delivered, increase the number of PAI teachers, and develop a learning evaluation system where the emphasis is on selfevaluation.

Keyword Problematics; Islamic Religious Education (PAI); Public Schools

Abstrak

Artikel ini mendeskripsikan tentang problematika pendidikan agama Islam di sekolah umum tingkat SMA. Adapun rumusan masalah yang diangkat adalah 1) Apa saja problem pendidikan agama Islam (PAI) yang terdapat di sekolah umum tingkat SMA; 2) Bagaimana solusi untuk mengatasi problematika pembelajaran PAI di sekolah umum tingkat SMA. Artikel ini ditulis menggunakan metode penelitian kualitatif. Adapun problematika 
PAI di sekolah umum tingkat SMA meliputi minat belajar peserta didik yang rendah dalam pembelajaran PAI, kurangnya alokasi waktu, problem pada pendidik, problem pada peserta didik, problem pada sarana dan prasarana, problem pada metode pembelajaran PAI, serta problem pada evaluasi pembelajaran. Solusi untuk mengatasi problema tersebut, diantaranya yaitu mengganti guru yang profesional, menemukan guru PAI yang profesional dalam bidangnya, setiap pendidik diikutsertakan dalam acara-acara seperti seminar, penyediaan sarana dan prasarana untuk pelaksanaan praktik mata pelajaran pendidikan agama Islam yang cukup, pendidik harus menguasai berbagai metode belajar supaya anak didik mudah memahami materi yang di sampaikan, menambah jumlah guru PAI, serta mengembangkan sistem evaluasi pembelajaran yang mana penekanannya pada evaluasi diri.

Kata Kunci Problematika; Pendidikan Agama Islam (PAI); Sekolah Umum

\section{A. Pendahuluan}

Pendidikan adalah usaha seseorang untuk meningkatkan kemampuan diri yang dilaksanakan melalui proses pengajaran dan pelatihan. Pendidikan dapat menjadi sebuah investasi masa depan bagi setiap manusia. Sebab, pendidikan adalah sesuatu yang dapat menentukan nasib manusia sebagai individu, umat maupun bangsa. Pendidikan adalah suatu bentuk tindakan sosial masyarakat karena adanya aspek sosial berupa ketergantungan individu satu sama lainnya dalam proses pembelajaran.

Agama Islam menghendaki agar manusia dididik dengan sebaikbaiknya agar ia dapat mewujudkan tujuan hidupnya dan dapat memenuhi tugas kekhalifahannya sebagaimana tujuan diciptakannya manusia yaitu menjadi manusia yang beriman, berilmu dan berakhlakul mulia. Sementara PAI adalah upaya mengembangkan potensi manusia dengan menanamkan nilai-nilai Islam pada diri peserta didik agar hidupnya mencapai kesempurnaan sebagai hamba Allah. ${ }^{1}$

Sekolah merupakan lembaga pendidikan formal yang memiliki fungsi sebagai tempat terlaksananya pendidikan. PAI pada tingkat

${ }^{1}$ Robiatul Awwaliyah dan Hasan Baharun, "Pendidikan Islam dalam Sistem Pendidikan Nasional (Telaah Epistemologi Terhadap Problematika Pendidikan Islam)," Jurnal IImiah DIDAKTIKA, Vol. 19, No. 1 (2018), h. 35; http://jurnal.arraniry.ac.id/ index.php/ didaktika/article/download/4193/2726, h. 35. 
sekolah menengah atas mempunyai tujuan yaitu untuk menumbuhkan dan meningkatkan keimanan yang dilakukan dengan cara memberi, memupuk pengetahuan dan mengajarkan pada siswa tentang agama Islam. ${ }^{2}$ Pembelajaran PAI di sekolah bermaksud agar siswa beriman dan tetap taqwa kepada Allah swt, berilmu dan berakhlak mulia. Akhlak mulia sebagai wujud dari pendidikan agama Islam tersebut mencakup etika, moral dan budi pekerti. ${ }^{3}$ Namun, Muslimin menyatakan bahwa dalam kenyataannya pendidikan agama hanya fokus pada transfer pengetahuan bukan pada pembentukan perilaku yang Islami. ${ }^{4}$ Seiring dengan berjalannya waktu, PAI kurang mendapat dukungan khususnya di sekolah umum tingkat SMA. Sehingga dalam pelaksanaan proses pembelajaran PAI muncul berbagai macam problematika yang menyebabkan proses pembelajaran mencapai hasil yang tidak sempurna, seperti kurangnya minat belajar peserta didik dalam pembelajaran PAI, kurangnya alokasi waktu, dan masih banyak lagi problem lainnya. Maka, kami penulis akan membahas beberapa hal mengenai problematika PAI di sekolah umum tingkat SMA. Pembahasan dimulai dari macam-macam problematika PAI di sekolah umum tingkat SMA dilanjutkan dengan upaya mengatasi problematika pembelajaran PAI di sekolah umum tingkat SMA.

\section{B. Problematika Pendidikan Agama Islam di Sekolah Umum Tingkat SMA}

Problematika berasal dari kata problem. Dalam kamus besar bahasa Indonesia problem artinya adalah masalah atau persoalan. ${ }^{5}$ Dalam sebuah pembelajaran pasti ada masalah yang akan ditemui. Tidak menutup kemungkinan juga terjadi pada PAI. Dalam

2 Arsyad dan Salahudin, "Hubungan Kemampuan Membaca Al Qur'an Dan Minat Belajar Siswa Dengan Hasil Belajar Pendidikan Agama Islam (PAI)," Edukasi: Jurnal Penelitian Pendidikan Agama dan Keagamaan, Vol. 16, No. 2 (2018), h. 180 http://jurnaledukasikemenag.org

3 Muhammad Irham, 'Evaluasi Program Pembelajaran PAI di SMA AlHidayah Medan' (Tesis, UIN Sumatera Utara Medan, 2016)

${ }^{4}$ Muslimin, "Problematika Pembelajaran Pendidikan Agama Islam Dan Upaya Solusi Guru Agama Dalam Pembinaannya di Sekolah," Tarbawiyah:Jurnal Ilmiah Pendidikan, Vol. 01, No. 2 (2017), h. 207.

${ }^{5}$ Susiana, "Problematika Pembelajaran PAI di SMKN 1 Turen," Jurnal AlThariqah, Vol. 2, No. 1, (2017), h. 73, https://journal.uir.ac.id/index.php/ althariqah/article. 
pembelajaran PAI banyak sekali masalah yang ditemui, yang permasalahan tersebut dapat menghambat proses pembelajaran. Dengan adanya permasalahan tersebut juga menghambat tercapainya tujuan pembelajaran PAI. Problem-problem tersebut yakni sebagai berikut:

\section{Minat Belajar Peserta Didik Rendah Pada Pembelajaran PAI}

Tingkatan minat belajar siswa pada dasarnya akan memberikan pengaruh terhadap hasil akhir proses pembelajaran. Untuk dapat melihat capaian hasil belajar siswa, sangat perlu adanya perhatian terhadap seluruh faktor yang berkaitan antara guru dengan siswa. Misalnya seperti perilaku siswa saat poses belajar mengajar berlangsung. Perilaku siswa dalam mengikuti proses kegiatan dapat menjadi salah satu indikasi akan tertarik atau tidaknya siswa terhadap pelajaran.

Crow and Crow menyebutkan bahwa minat adalah suatu rasa dimana seseorang tertarik pada suatu hal atau kegiatan tertentu, sesuai keinginannya sendiri. Minat pada dasarnya adalah penerimaan atau suatu hubungan antara diri sendiri dan sesuatu diluar diri. Semakin kuat atau dekat hubungan tersebut, semakin besar minat. Minat belajar PAI, kecenderungan berupa suatu keinginan yang tampak pada diri siswa untuk selalu memperhatikan pembelajaran PAI, namun bila siswa kurang memiliki keinginan untuk belajar PAI maka ia tidak akan bisa mencapai hasil belajar yang maksimal. ${ }^{6}$

Problem kurangnya minat peserta didik di sekolah umum tingkat SMA untuk mengikuti pembelajaran PAI karena dipengaruhi beberapa faktor. Adapun faktornya dipengaruhi oleh lingkungan keluarga, sekolah, dan masyarakat. Pertama, faktor keluarga. Minat belajar siswa SMA dipengaruhi oleh cara mendidik orangtua terhadap anaknya. Orangtua yang terbiasa tidak mengajarkan PAI saat di rumah maka biasanya akan berdampak juga saat di sekolah. Di sekolah anak tersebut akan merasa tidak tertarik pada pembelajaran PAI.

Kedua, faktor lingkungan sekolah. Para siswa SMA lebih tertarik jika guru menggunakan media pembelajaran berbasis teknologi. Oleh karena guru PAI terbiasa menggunakan buku sebagai media pembel ajaran maka hal tersebut menjadikan siswa SMA minat belajar PAI

6 Vina Mayrani, 'Hubungan Minat Belajar Dengan Prestasi Belajar Pendidikan Agama Islam Kelas XI Di SMA N 1 Way Pengubuan Lampung Tengah' (Skripsi, IAIN Metro, 2018) 
menurun. Ketiga, faktor lingkungan masyarakat. Lingkungan masyarakat merupakan faktor pembentuk kepribadian siswa, karena siswa akan menyesuaikan diri terhadap pergaulan sehari-hari. Seorang siswa yang tidak memiliki kemauan untuk mempelajari PAI, maka ia akan merasa bosan. Untuk itu, siswa-siswa SMA harus mempunyai motivasi belajar maupun itu muncul dengan sendirinya dalam diri sendiri atau karena mendapat motivasi dari orang lain. ${ }^{7}$

\section{Kurangnya Alokasi Waktu}

Alokasi waktu disini berkaitan dengan peran seorang pendidik. Dalam PAI, pendidik dituntut untuk bersikap profesional dalam melaksanakan tugasnya. Seorang pendidik dapat dikatakan mempunyai sikap profesional bila ia komitmen terhadap mutu proses pengajaran dan hasil kerjanya. ${ }^{8}$ Problem yang muncul yaitu saat mata pelajaran PAI diletakkan pada saat jam pelajaran terakhir, maka siswa SMA akan merasa jenuh dan pada akhirnya tidak dapat memahami materi pelajarannya. Misal, ketika mata pelajaran Sejarah Kebudayaan Islam (SKI) diletakkan pada jam pelajaran terakhir bahkan guru menggunakan metode ceramah dalam menyampaikan materi maka hal tersebut mengakibat siswa terganggu konsentrasinya dalam belajar PAI di waktu siang cuacanya panas dan merasa jenuh untuk mendengarkan materi yang disampaikan.

\section{Problem Pada Pendidik}

Pendidikan agama adalah pendidikan yang memberikan ketrampilan, dan membentuk sikap peserta didik dalam mengamalkan ajaran agama pada semua jalur. PAI bertujuan untuk meningkatkan keimanan, pemahaman, penghayatan dan pengamalan peserta didik tentang agama Islam, sehingga menjadi manusia muslim yang beriman tetap taqwa kepada Allah swt serta mempunyai akhlak yang mulia dalam kehidupan pribadinya. ${ }^{9}$

Permasalahannya, penyelenggaraan PAI di sekolah umum belum optimal karena kurangnya jumlah guru PAI, meskipun sudah banyak para sarjana Indonesia dari PAI, namun terkadang para sarjana tidak

7 Susiana, "Problematika Pembelajaran PAI di SMKN 1 Turen", h. 75.

${ }^{8}$ Susiana, "Problematika Pembelajaran PAI di SMKN 1 Turen", h. 77.

${ }^{9}$ Suprapto, "Kebutuhan Guru Pendidikan Agama Islam di Sekolah," Jurnal Penelitian Pendidikan Agama dan Keagamaan, Vol. 16, No. 2 (2018), http://jurnaledukasi kemenag.org/index.php/edukasi 
semuanya menjadi guru PAI di sekolah. Hal ini mengakibatkan proses pembelajaran PAI di sekolah umum dilakukan oleh guru yang bukan bidangnya maka akan mengakibatkan menurunya kualitas PAI di sekolah umum. Padahal guru PAI sendiri memiliki tugas yang lebih penting dari pada pelajaran umum lainya, ini karena guru PAI bukan hanya harus mampu memberi pemahaman materi kepada peserta didik, tetapi seorang guru PAI juga harus mampu memberikan kepribadian peserta didik sesuai dengan ajaran agama Islam. Guru PAI juga memiliki tanggung jawab bukan hanya kepada peserta didik saja ia juga bertanggung jawa kepada Allah swt atas apa yang diajarkannya.

\section{Problem Pada Peserta didik}

Mu'allimah $^{10}$ menyatakan bahwa peserta didik pada suatu lembaga pendidikan tentu memiliki latar belakang kehidupan beragama yang berbeda-beda. Ada peserta didik yang taat beragama, namun ada juga yang berasal dari keluarga yang kurang taat pada agama, bahkan ada yang berasal dari keluarga yang tidak perduli dengan agama. Hal ini tentunya sangat mempengaruhi keberhasilan PAI di sekolah. Bagi peserta didik yang berasal dari keluarga yang kurang taat pada agama atau bahkan tidak peduli terhadap agama, maka perlu diperhatikan, sebab jika tidak, maka peserta didik tidak akan peduli terhadap PAI, lebih parahnya lagi mereka menganggap remeh PAI. Faktor-faktor yang mempengaruhi peserta didik seperti motivasi belajar, keluarga kurang harmonis, keadaan ekonomi, problem intelegensi, bakat dan minat, sikap orang tua yang tidak memperhatikan pendidikan anaknya dan lain-lain.

Memperhatikan dan mencermati problem peserta didik tersebut, maka perlulah kerjasama antara pendidik dan orangtua peserta didik. Pendidik perlu mengetahui sedikit kondisi tentang suasana rumah, tempat anak itu hidup, sehingga pendidik mengetahui suasana hidup keagamaannya dan bagaimana pandangan terhadap perlunya PAI bagi putra-putrinya. Namun, selama ini bahwa PAI berpusat dan menjadi tangung jawab guru-guru agama saja, orang tua menyerahkan sepenuhnya PAI pada guru agama di sekolah. Padahal, kerjasama antara orangtua dan pendidik juga sangat penting dilakukan.

${ }^{10} \mathrm{Mu}$ 'allimah, Problematika pembelajaran pendidikan agama Islam di SMA Negeri 3 Medan, (Thesis UIN Sumatera Utara, 2014) 


\section{Problem Pada Sarana dan Prasarana}

Sarana menjadi salah satu pendukung proses kelancaran pembelajaran, kelengkapan dan sarana dapat membantu guru dalam meyelenggarakan proses pembelajaran. Alat pendidikan menurut Barnadib dalam Jalaludin dan Umar Said ialah suatu tindakan, perbuatan, suasana ataupun benda yang sengaja diadakan untuk mencapai suatu tujuan didalam pendidikan. Jadi, alat pendidikan tidak terbatas hanya pada benda-benda yang kongkrit saja, tetapi juga berupa nasihat, tuntutan, bimbingan, contoh, hukuman, ancaman, dan lain-lainnya. ${ }^{11}$

\section{Problem Pada Metode Pembelajaran PAI}

Metode pembelajaran yaitu suatu cara yang dapat digunakan pendidik dalam hal penyampaian bahan pelajaran agar peserta didik dapat mengetahui, memahami, menghayati, mengamalkan dan menguasai bahan pelajaran tersebut. Sudjana mengatakan, metode pembelajaran ialah cara yang digunakan oleh pendidik dalam mengadakan hubungan dengan peserta didik pada saat kegiatan pengajaran berlangsung. ${ }^{12}$ Semantara itu, Sabri ${ }^{13}$ mengemukakan bahwa metode pembelajaran merupakan cara-cara atau teknik penyajian bahan pelajaran yang digunakan pendidik pada saat pembelajaran baik secara individu maupun kelompok kepada peserta didik. Ahmadi dan Triprasetya mengemukakan bahwa metode mengajar yaitu suatu pengetahuan tentang cara-cara mengajar yang digunakan oleh pendidik, atau teknik penyajian yang dikuasai pendidik untuk mengajar bahan pelajaran kepada peserta didik di dalam kelas, baik secara individual atau secara kelompok agar pelajaran itu dapat diserap, dipahami dan dimanfaatkan oleh peserta didik dengan baik, semakin baik metode mengajar, semakin efektif pula pencapaian tujuan. ${ }^{14}$ Jadi dapat disumpulkan bahwa metode pembelajaran adalah

${ }^{11}$ Jalaluddin dan Usman Said, Filsafat Pendidikan Islam dan Perkembangan Pemikirannya, (Jakarta: Raja Grafindo, 1994), h. 57.

12 Nana Sudjana, Dasar-Dasar Belajar Mengajar, (Bandung: Sinar Baru Algensindo, 2005).

13 Ahmad Sabri, Strategi Belajar Mengajar Micro Teaching, (Jakarta: Quantum teaching, 2005), h. 52-53

${ }^{14}$ Abu Ahmadi dan Joko Tri Prasetya, Strategi Belajar Mengajar, (Bandung: Pustaka Setia, 1997) Lihat juga dalam Halid Hanafi, dkk., Profesionalisme Guru 
cara penyampaian materi-materi pelajaran yang digunakan oleh pendidik kepada peserta didik agar mereka dapat memahami, mengetahui dan menggunakan materi pelajaran yang diberikan.

Metode pembelajaran yang baik adalah metode pembelajaran yang sesuai dengan materi dan tujuan pembelajaran. Selain itu, variasi metode juga membantu peserta didik berpikir kreatif dan inovatif dari pada hanya menggunakan metode ceramah yang menyebabkan peserta didik bosan, pasif dan pendidik pun akan merasa cepat lelah karena pembelajaran hanya dilakukan satu arah. ${ }^{15}$ Sementara menurut Hujair ${ }^{16}$, selama ini sangat dirasakan bahwa proses pendidikan Islam terkesan menganut asas subject matter oriented yang membebani peserta didik dengan informasi-informasi yang kognitif dan motorik yang kurang relevan dengan kebutuhan dan tingkat perkembangan psikologi peserta didik. Pendekatan metodologis pendidik masih terpaku pada orientasi tradisionalistis sehingga tidak mampu menarik minat murid pada pelajaran PAI.

Selama ini memang masih sangat dirasakan bahwa metode pembelajaran PAI kurang bervariasi. Metode ceramahlah yang sangat sering digunakan. Pendidik merasa dengan metode ceramah pendidik dapat mengawasi peserta didik yang berbuat keributan di kelas agar tidak mengganggu kelas lain, namun pemahaman peserta didik terfokus pada apa yang disampaikan oleh pendidik kemudian tidak terlalu banyak waktu yang terbuang, namun, akibatnya pendidik cepat merasa kelelahan dan peserta didik menjadi tidak aktif karena pembelajaran hanya dilakukan satu arah.

Sementara itu menurut Wina Sanjaya ${ }^{17}$, bahwa dalam kurikulum 2013, pendekatan kurikulum berpusat pada peserta didik dan model pembelajaran kooperatif, discovery learning. Model pembelajran ini menuntut peserta didik untuk berusaha mencari berbagai informasi mengenai materi pelajaran secara berkelompok (diskusi) sehingga tugas pendidik lebih banyak sebagai fasilitator dan pembimbing bagi peserta didiknya. Tantangan bagi guru yaitu guru dituntut memahami

dalam Pengelolaan Kegiatan Pembelajaran di Sekolah, (Yogyakarta: Deepublish, 2018), h. 83

${ }^{15}$ Dja'far Siddik, Konsep Dasar Ilmu Pendidikan Islam, (Cipta Pustaka, 2006)

${ }^{16}$ Hujair AH.Sanaky, Paradigma Pendidikan Islam: Membangun Masyarakat Madani Indonesia, (Yogyakarta: Safiria Insani Press, 2003)

17 Wina Sanjaya, Strategi Pembelajaran Berorientasi Standar Proses Pendidikan, (Jakarta : Prenada Media Group, 2010), h. 148 
jenis-jenis atau tipe-tipe pembelajaran kooperatif agar dapat menerapkannya dengan baik di dalam kelas bukan hanya sebatas diskusi tanpa makna.

\section{Problem Pada Evaluasi Pembelajaran}

Evaluasi merupakan suatu kegiatan pembelajaran untuk melihat apakah suatu program yang direncanakan dapat tercapai atau tidak, berharga atau tidak, serta dapat digunakan untuk melihat tingkat efisiensi pelaksanannya. Evaluasi berhubungan dengan keputusan nilai. Menurut Gronlund, evaluasi merupakan proses yang sistematis untuk mengumpulkan, menganalisis, dan menginterpretasikan informasi untuk menentukan tingkat penguasaan peserta didik terhadap tujuan pembelajaran. ${ }^{18}$ Kemudian, dalam PP No.19 Tahun 2005 tentang standar penilaian Bab X pasal 64 ayat 3 telah disebutkan bahwa penilaian hasil belajar kelompok mata pelajaran agama dan akhlak mulia, meliputi; (a) Pengamatan terhadap perubahan perilaku dan sikap untuk menilai perkembangan afeksi dan kepribadian peserta didik; dan (b) Ujian, ulangan dan penugasan untuk mengukur aspek kognitif peserta didik.

Selama ini memang sangat dirasakan sekali bahwa sistem evaluasi PAI, bentuk soal-soal ujian agama Islam menunjukkan prioritas utama pada kognitif dan jarang pertanyaan tersebut mempunyai bobot muatan nilai dan makna spiritual keagamaan yang fungsional dalam kehidupan sehari-hari. Walaupun dalam pembelajarannya, terdapat juga materi pelajaran berupa praktik, namun tetap saja ketika dilaksanakan ujian, yang diukur ranah kognitif dan yang dimasukkan ke dalam raport juga nilai dari ranah kognitif. Akibatnya, sering dijumpai peserta didik yang kurang pandai membaca al-Qur'an dengan baik tapi di raport mendapat nilai yang tinggi bahkan terkadang lebih tinggi nilainya dibandingkan dengan peserta didik yang pandai membaca al-Qur'an, sering dijumpai peserta didik yang malas dan merasa terpaksa mengikuti pelajaran agama tetapi ketika dievaluasi mendapatkan nilai yang lebih tinggi dari pada peserta didik yang rajin dan aktif mengikuti pelajaran agama. Tentu evaluasi seperti ini merugikan bagi peserta didik. Jika cara mengevaluasi terus menerus di

${ }^{18}$ Ibadullah Malawi dan Endang Sri Maruti, Evaluasi Pendidikan, (Magetan: CV. AE Media Grafika, 2016), h. 1 
lakukan seperti ini tentunya peserta didik penuh kognisinya dengan pengetahuan namun tidak memiliki akhlak mulia.

Selanjutnya, dalam kurikulum 2013, evaluasi mencakup tiga ranah, kompotensi inti adalah KI 1 untuk ranah afkektif atau yang disebut dengan sikap spiritual yaitu sikap yang mengatur antara peserta didik dengan Tuhannya, KI 2 untuk ranah afektif atau sikap sosial, sikap yang mengatur antara peserta didik dengan orang lain dan alam sekitar, KI 3 untuk ranah kognitif atau pengetahuan dan KI 4 yaitu ranah psikomotorik atau ketrampilan. Untuk melaksanakan evaluasi ranah kognitif (KI 3), dilakukan ujian tertulis, tes lisan berupa pertanyaan dan penugasan. Evaluasi ranah psikomotorik (KI 4) biasanya melakukan ujian praktik. Untuk evaluasi ranah afektif (KI 2) dapat dinilai selama kegiatan belajar berlangsung, bagaimana peserta didik bersikap kepada teman-temanya di kelas, bersikap kepada pendidik ketika berdiskusi. Namun, untuk mengevaluasi KI 1 (sikap spiritual) dirasa sangat sulit karena keterbatasan waktu pendidik untuk mengawasi kegiatan keagamaan yang dilakukan peserta didik, misalnya salat lima waktu, membaca al-Quran, bersedekah, berkata yang baik, husnudzan kepada Allah, dan lain-lain. Guru PAI hanya memiliki 2 jam pelajaraan untuk setiap minggunya dan harus memahami dan mengidentifikasi paling sedikit 30 orang siswa dalam setiap kelas. Tentunya sangat diperlukan kerja sama antara guru PAI dan orangtua peserta didik agar sikap spiritual peserta didik tetap diamati dan di evaluasi. Selain itu pula, seharusnya PAI sebaiknya masuk ujian nasional, sehingga menjadi bahan untuk mempertimbangkan peserta didik lulus atau tidak lulus di suatu lembaga pendidikan. Ujiannya tidak hanya sekedar mengukur kemampuan yang bersifat psikomotor atau praktik serta sikap peserta didik sebagai orang yang menganut ajaran Islam. ${ }^{19}$

\section{Solusi Problematika Pendidikan Agama Islam di Sekolah Umum Tingkat SMA}

Sebenarnya untuk mengatasi problem dalam PAI di sekolah umum pada tinggkat SMA dapat dilakukan dengan beberapa cara, diantaranya adalah:

${ }^{19} \mathrm{Mu}$ 'allimah, Problematika pembelajaran pendidikan agama Islam di SMA Negeri 3 Medan, h. 27-28 
1) Mengganti guru yang profesional sesuai dalam bidang PAI tersebut, supaya dalam penyampaian materi siswa tidak salah pemahaman. Dengan digantinya guru yang profesional maka tujuan pembelajaran PAI akan tercapai dengan baik, dan kualitas pembelajaran PAI di sekolah akan membaik. Dengan adanya guru profesional akan mudah mencapai tujuan pembelajaran PAI.

2) Menemukan guru PAI yang profesional dalam bidangnya. Sebab guru yang mempunyai keahlian dalam bidang PAI akan membantu peserta didik untuk mengenal agama Islam dengan baik, walaupun kurang mendapat dukungan dari keluarga tapi ada guru yang selalu memberi semangat dan pelajaran yang baik.

3) Pihak sekolah mengusahakan pada setiap pendidik untuk diikutsertakan dalam acara seminar, workshop ataupun MGMP untuk dapat meningkatkan wawasan dan kompetensi mereka dalam mendidik khususnya dalam pendidikan agama Islam. ${ }^{20}$

4) Penyediaan sarana dan prasarana untuk pelaksanaan praktik mata pelajaran pendidikan agama Islam yang cukup. Dengan adanya sarana prasarana yang memadai akan memudahkan pendidik dalam penyampaian materi. Contohnya pada saat praktik mengkafani jenazah akan lebih mudah bila menggunakan alat bantu. Dengan sarana prasarana yang memadai membuat peserta didik lebih semangat dalam belajar. Sarana dan prasarana yang ada dimanfaatkan dengan baik untuk membantu proses belajar mengajar sehingga tujuan pendidikan dapat tercapai. ${ }^{21}$

5) Setiap pendidik harus berusaha menggunakan berbagai metode dan media pembelajaran yang bervariasi agar mampu menciptakan suasana belajar-mengajar yang menyenangkan, sehingga peserta didik dapat merasa senang dalam mengikuti pembelajaran serta mudah dalam menerima dan memahami materi pelajaran yang diberikan oleh pendidik. ${ }^{22}$ Sebagai pendidik yang baik harusnya mengetahui metode yang sesuai digunakan dalam pembelajaran. Pendidik harus menguasai berbagai metode belajar supaya anak didik mudah memahami materi yang di sampaikan. Oleh sebab itu

${ }^{20} \mathrm{Mu}$ 'allimah, Problematika pembelajaran pendidikan agama Islam di SMA Negeri 3 Medan

${ }^{21} \mathrm{Mu}$ 'allimah, Problematika pembelajaran pendidikan agama Islam di SMA Negeri 3 Medan

${ }^{22} \mathrm{Mu}$ 'allimah, Problematika pembelajaran pendidikan agama Islam di SMA Negeri 3 Medan

Tarbawiyah: Jurnal Ilmiah Pendidikan :: Volume 04; Nomor 1, Juni 2020 p-ISSN: 2579-3241; e-ISSN: 2579-325X

https://doi.org/DOI.10.32332/tarbawiyah.v4i1.1950 
pendidik harus belajar tentang metode pembelajaran, supaya peserta didik senang dan mudah memahami apa yang di ajarkan oleh pendidik.

6) Menambah jumlah guru PAI. Dengan adanya guru yang professional bukan masalah sulit untuk mengatasi tentang evaluasi. Di sekolahan umum guru PAI seharusnya bukan hanya satu, namun harus lebih dari itu, karena banyak kelas yang harus di ajar. Bila hanya ada satu pendidik pasti akan menghambat berkualitasnya proses pembelajaran PAI.

7) Mengembangkan sistem evaluasi pembelajaran yang mana penekanannya pada eval uasi diri. Upaya ini menempatkan guru sebagai fasilitator yang harus membantu peserta didiknya mengetahui tingkat kemajuan proses belajarnya. ${ }^{23}$

\section{Kesimpulan}

Berdasarkan uraian dari pembahasan di atas dapat diambil kesimpulan yaitu problematika Pendidikan Agama Islam di sekolah umum tingkat SMA meliputi: (1) minat belajar peserta didik yang rendah dalam pembelajaran PAI, (2) kurangnya alokasi waktu, (3) problem pada pendidik, (4) problem pada peserta didik, (5) problem pada sarana dan prasarana, (6) problem pada metode pembelajaran PAI, serta (7) problem pada evaluasi pembelajaran. Sedangkan solusi dari problematika Pendidikan Agama Islam di sekolah umum tingkat SMA yaitu dengan cara mengganti guru yang profesional, menemukan guru PAI yang profesional dalam bidangnya, setiap pendidik diikutsertakan dalam acara-acara seperti seminar, workshop, penyediaan sarana dan prasarana untuk pelaksanaan praktik mata pelajaran pendidikan agama Islam yang cukup, pendidik harus menguasai berbagai metode belajar supaya anak didik mudah memahami materi yang di sampaikan, menambah jumlah guru PAI, dan mengembangkan sistem evaluasi pembelajaran yang mana penekanannya pada evaluasi diri.[]

${ }^{23}$ Hilyah Ashoumi, "Pendayagunaan Lingkungan Sekolah Religius Untuk Memaksimalkan Pencapaian Kurikulum PAI," Dinamika, Vol. 1, No. 1, (2016), h. 40; http://ejournal.unwaha.ac.id/index.php/dinamika/article/view/103, 


\section{Daftar Pustaka}

Abu Ahmadi dan Joko Tri Prasetya, Strategi Belajar Mengajar, Bandung: Pustaka Setia, 1997

Ahmad Sabri, Strategi Belajar Mengajar Micro Teaching, Jakarta: Quantum teaching, 2005

Arsyad dan Salahudin, "Hubungan Kemampuan Membaca Al Qur'an Dan Minat Belajar Siswa Dengan Hasil Belajar Pendidikan Agama Islam (PAI)," Edukasi: Jurnal Penelitian Pendidikan Agama dan Keagamaan, Vol. 16, No. 2 (2018); http://jurnaledukasi kemenag.org

Dja'far Siddik, Konsep Dasar Ilmu Pendidikan Islam, Cipta Pustaka, 2006

Halid Hanafi, dkk., Profesionalisme Guru dalam Pengelolaan Kegiatan Pembelajaran di Sekolah, Yogyakarta: Deepublish, 2018

Hilyah Ashoumi, "Pendayagunaan Lingkungan Sekolah Religius Untuk Memaksimalkan Pencapaian Kurikulum PAI," Dinamika, Vol. 1, No. 1, (2016), http://ejournal.unwaha.ac.id/index.php/ dinamika/ article/ view/103,

Hujair AH.Sanaky, Paradigma Pendidikan Islam: Membangun Masyarakat Madani Indonesia, Yogyakarta: Safiria Insani Press, 2003

Ibadullah Malawi dan Endang Sri Maruti, Evaluasi Pendidikan, Magetan: CV. AE Media Grafika, 2016

Jalaluddin dan Usman Said, Filsafat Pendidikan Islam dan Perkembangan Pemikirannya, Jakarta: Raja Grafindo, 1994

Muhammad Irham, "Evaluasi Program Pembelajaran PAI di SMA AlHidayah Medan", Tesis, UIN Sumatera Utara Medan, 2016 
Muslimin, "Problematika Pembelajaran Pendidikan Agama Islam Dan Upaya Solusi Guru Agama Dalam Pembinaannya di Sekolah," Tarbawiyah: Jurnal Ilmiah Pendidikan, Vol. 01, No. 2, (2017)

Nana Sudjana, Dasar-Dasar Belajar Mengajar, Bandung: Sinar Baru Algensindo, 2005

Robiatul Awwaliyah dan Hasan Baharun, "Pendidikan Islam dalam Sistem Pendidikan Nasional (Telaah Epistemologi Terhadap Problematika Pendidikan Islam)," Jurnal Ilmiah DIDAKTIKA, Vol. 19, No. 1 (2018), http://jurnal.ar-raniry.ac.id/index.php/ didaktika/article/download/ 4193/2726.

Suprapto, "Kebutuhan Guru Pendidikan Agama Islam di Sekolah," Jurnal Penelitian Pendidikan Agama dan Keagamaan, Vol. 16, No. 2 (2018), http://jurnaledukasi kemenag.org/index.php/edukasi

Susiana, "Problematika Pembelajaran PAI di SMKN 1 Turen," Jurnal AlThariqah, Vol. 2, No. 1, (2017) https://journal.uir.ac.id/index. Php/althariqah/article.

Vina Mayrani, "Hubungan Minat Belajar Dengan Prestasi Belajar Pendidikan Agama Islam Kelas XI Di SMA N 1 Way Pengubuan Lampung Tengah" Skripsi, IAIN Metro, 2018

Wina Sanjaya, Strategi Pembelajaran Berorientasi Standar Proses Pendidikan, Jakarta: Prenada Media Group, 2010 